\title{
STUDI PERBANDINGAN HASIL BELAJAR KIMIA ANTARA MODEL PEMBELAJARAN TEAM QUIZ DENGAN MODEL PEMBELAJARAN COURSE REVIEW HORAY PADA SISWA KELAS XI MIA SMAN 1 LINGSAR Nita Wardani', Muntari Muntari', Saprizal Hadisaputra ${ }^{2}$, I Nyoman Loka ${ }^{2}$ \\ ${ }^{1}$ Mahasiswa Prodi Pendidikan Kimia, Universitas Mataram \\ ${ }^{2}$ Dosen Prodi Kimia, Universitas Mataram \\ Program Studi Pendidikan Kimia Fakultas Keguruan dan Ilmu Pendidikan \\ Universitas Mataram \\ Keperluan korespondensi, email: Wardaninita1996@gmail.com
}

\begin{abstract}
Abstrak
Penelitian ini bertujuan untuk mengetahui perbedaan pengaruh hasil belajar kimia yang signifikan antara model pembelajaran Team Quiz dengan model pembelajaran Course Review Horay pada siswa SMAN 1 Lingsar Tahun Ajaran 2018/2019. Jenis penelitian yang digunakan berupa penelitian eksperimen semu dengan desain penelitian Nonequivalent Control Group Design.Populasi dalam penelitian ini adalah seluruh siswa kelas XI MIA SMAN 1 Lingsar.Sampel dalam penelitian ini yaitu kelas XI MIA 3 dan XI MIA 4 yang ditentukan melalui teknik pengambilan sampel Purposive Sampling. Variabel bebas dalam penelitian ini adalah model pembelajaran Team Quiz untuk kelas eksperimen A dan model pembelajaran Course Review Horay untuk kelas eksperimen B. Variabel terikatnya adalah hasil belajar kimia siswa dalam ranah kognitif. Teknik pengumpulan data dilakukan dengan pemberian pretest dan posttest dalam bentuk tes pilihan ganda untuk mengukur hasil belajar siswa.Pengujian hipotesis dilakukan dengan menggunakan Gain uji-t dengan pengambilan keputusan didasarkan pada uji hipotesis dua pihak.Gain uji-t digunakan untuk menganalisis data hasil belajar kimia siswa, didapatkan $t_{\text {hitung }}(0,021) \leq t_{\text {tabel }}(2,021)$. Hasil tersebut menunjukkan bahwa tidak ada perbedaan pengaruh hasil belajar kimia yang signifikan antara model pembelajaran Team Quiz dengan model pembelajaran Course Review Horay pada siswa kelas XI MIA SMAN 1 Lingsar.
\end{abstract}

Kata Kunci:Model pembelajaran Team Quiz, Model Pembelajaran Course Review Horay, Hasil Belajar.

\section{THE COMPARISON STUDY OF CHEMICAL LEARNING OUTCOMES BETWEEN QUIZ TEAM LEARNING MODEL WITH USING COURSE REVIEW HORAY LEARNING MODEL IN XI MIA CLASS' STUDENTS OF SMAN 1 LINGSAR}

\begin{abstract}
This study was aimed to determine the significant differences of chemistry learning outcomes between Team Quiz learning models with Course Review Horay learning models in XI MIA Class' students of SMAN 1 Lingsar academic year 2018/2019. The type of research used in this study was a quasi-experimental study with the Nonequivalent Control Group Design. The population in this study were all students of class XI MIA SMAN 1 Lingsar. The samples in this study were class XI MIA 3 and XI MIA 4 which were determined by purposive sampling technique. The independent variable in this study was Team Quiz learning model for experimental class A and Course Review Horay learning model for experimental class $B$. The dependent variable is the learning outcomes of students
\end{abstract}




\section{Chemistry Education Practice,1 (2), 2018 - 15}

Wardani, Muntari, Hadisaputra, Loka

in the cognitive domain. Data collection techniques were carried out by giving pretest and posttest in the form of multiple choice tests to measure students learning outcomes. Hypothesis testing process wasconducted by using the gaint-test with decision making based on the two-party hypothesis test. Ttest results were used to analyze students' chemistry learning outcomes data, in which the result tcount $(0,021) \leq$ ttable $(2,021)$. These results indicated that there were no significant differences of chemistry learning outcomes between Team Quiz learning models with Course Review Horay learning models in XI MIA Class'students of SMAN 1 Lingsar.

Keywords: Team Quiz learning model, Course Review Horay Learning Model, Learning Outcomes.

\section{PENDAHULUAN}

Pembelajaran yang baik di sekolah adalah pembelajaran yang memberikan kesempatan kepada siswa untuk melakukan kegiatan belajar secara aktif (Pebriana, dkk., 2018). Sagala (2010) mengemukakan pembelajaran aktif dimaksudkan bahwa dalam proses pembelajaran guru harus menciptakan suasana pembelajaran yang dinamis dan penuh aktivitas, sehingga peserta didik aktif untuk bertanya, mempertanyakan, dan mengemukakan gagasan. Mewujudkan pembelajaran yang dapat melibatkan keaktifan siswa agar pembelajaran bervariasi dan tidak membosankan bukanlah perkara mudah. Karp dan Yoels mengemukakan bahwa dari 40 siswa dalam kelas, hanya dua sampai tiga siswa yang mendominasi separuh dari interaksi kelas (Lie, 2007). Beberapa hasil penelitian dari Sagala (2010) terkait dengan keterlibatan siswa dalam proses pembelajaran menunjukkan bahwa selama ini pembelajaran yang berlangsung disekolah juga cenderung menunjukkan (1) guru lebih banyak ceramah; (2) pengelolaan cenderung klasikal dan kegiatan belajar kurang bervariasi; dan (3) interaksi pembelajaran searah.

Berdasarkan hasil observasi di sekolah, guru masih menerapkan model pembelajaran konvensional yang didominasi oleh metode ceramah. Metode ceramah jika sering digunakan akan menimbulkan kejenuhan pada diri siswa yang dalam proses belajar mengajar hanya duduk, mendengar, melihat dan menerima pelajaran dari guru secara pasif, sehinggamenyebabkan minat dan motivasi siswa dalam belajar kimia menjadi rendah. Hal ini dapat dilihat dari banyaknya siswa yang mengantuk, berbicara dengan temannya saat proses belajar mengajar berlangsung dan kelas menjadi tidak kondusif. Hal inilah yang menyebabkan proses belajar mengajar kurang efektif dan berdampak pada hasil belajar kimia siswa masih rendah atau rata-rata masih di bawah Kriteria Ketuntasan Minimal (KKM) yaitu 75 . Hal itu dapat dilihat dari nilai rata-rata semester ganjil siswa kelas XI MIA Tahun Pelajaran 2017/2018 sebagai berikut.

Tabel 1. Nilai Rata-Rata Ujian Tengah Semester Ganjil Mata Pelajaran Kimia Siswa Kelas XI MIA SMAN 1 Lingsar Tahun Ajaran 2017/2018

\begin{tabular}{c|c|c|c}
\hline No. & Kelas & $\begin{array}{c}\text { Jumlah } \\
\text { siswa }\end{array}$ & $\begin{array}{c}\text { Nilai rata- } \\
\text { rata }\end{array}$ \\
\hline 1 & XI MIA 1 & 32 & 46,44 \\
\hline 2 & XI MIA 2 & 32 & 47,00 \\
\hline 3 & XI MIA 3 & 34 & 50,21 \\
\hline 4 & XI MIA 4 & 33 & 51,79 \\
\hline
\end{tabular}

Sumber data :Arsip guru 2018

Salah satu upaya yang dapat dilakukan untuk mengurangi masalah yang dihadapi tersebut adalah dengan menerapkan model pembelajaran yang menarik dan sesuai dengan materi pelajaran yang dapat meningkatkan hasil belajar siswa, mudah memahami materi kimia yang diajarkan, dan mendapatkan pengalaman belajar yang lebih baik dan menyenangkan agar hasil belajar siswa dapat meningkat dan lebih baik dari sebelumnya. Salah satu model pembelajaran yang dapat digunakan adalah model pembelajaran kooperatif yaitu model pembelajaran Team Quiz dan model pembelajaran Course Review Horay.

$$
\text { Menurut Dalvi (2006) model }
$$
pembelajaran TQ merupakan salah satu tipe pembelajaran yang mampu meningkatkan keaktifan siswa dalam proses belajar. Dalam tipe ini siswa dibentuk dalam kelompok-kelompok kecil dengan masing-masing anggota kelompok mempunyai tanggungjawab yang sama atas keberhasilan kelompoknya dalam memahami materi dan menjawab soal. Tipe TQ ini diawali dengan guru menerangkan materi secara klasikal, lalu siswa dibagi kedalam kelompok. Semua anggota kelompok bersama-sama mempelajari materi tersebut, saling memberi 


\section{Chemistry Education Practice,1 (2), 2018 - 16}

Wardani, Muntari, Hadisaputra, Loka

arahan, saling memberikan pertanyaan, dan jawaban untuk memahami mata pelajaran tersebut. Setelah selesai materi maka diadakan suatu pertandingan akademis. Dengan adanya pertandingan akademis ini maka terciptalah kompetisi antar kelompok, para siswa akan senantiasa berusaha belajar dengan motivasi yang tinggi agar dapat memperoleh nilai yang tinggi dalam pertandingan.

Ada beberapa tahapan dalam proses pembelajaran menggunakan model Team Quiz, seperti yang dijelaskan oleh Suprijono(2009) yaitu:penyampaian materi, pembagian kelompok, diskusi kelompok, satu kelompok membuat pertanyaan dan kelompok lain menjawab, melakukan tanya jawab, menyimpulkan pembelajaran, dan memberikan penghargaan.

Model pembelajaran Course Review Horay adalah suatu model pembelajaran dengan pengujian pemahaman menggunakan kotak yang diisi dengan nomor untuk menuliskan jawabannya, yang paling dulu mendapatkan tanda benar langsung berteriak horay (Dwitantra, 2010).

Ada beberapa tahapan dalam proses pembelajaran menggunakan model Course Review Horay, seperti yang dijelaskan oleh Suprijono(2009) yaitu:penyampaian materi, pembagian kelompok, diskusi kelompok, membuat kotak-kotak kecil, membacakan soal diskusi, membacakan jawaban yang benar, kelompok yang menjawab benar lebih cepat berteriak horay dan kelompok lain menjawab, memberikan penghargaan dan menyimpulkan pembelajaran.

Kedua model pembelajaran tersebut membuat pembelajaran lebih menyenangkan dan tidak membosankan di kelas sehingga model pembelajaran Team Quiz dan Course Review Horay diyakini dapat meningkatkan hasil belajar siswa pada materi hidrokarbon.Materi hidrokarbon yang lebih menjelaskan mengenai strukutur kimia yang rumit dan agak sulit dipahami apabila siswa tidak tertarik mempelajarinya. Melalui model pembelajaran Team Quizdan Course Review Horay siswa akan lebih mudah memahami materi hidrokarbon karena adanya diskusi kelompok yang memungkinkan bagi antar siswa untuk saling bertanya apabila kurang mengerti materi yang diajarkan oleh guru. Selain itu, siswa juga akan lebih mengingat materi apabila siswa terjun langsung dalam menjawab soal-soal yang diberikan oleh guru.
Perbedaan model Team Quiz dan Course Review Horayterletak pada tugas belajar siswa pada saat bermain game. Pada model pembelajaran TQsiswa diberikan tugas membuat pertanyaan-pertanyaan sederhana terkait materi pembelajaran bersama kelompoknya untuk dijadikan kuis dan menjawab pertanyaan dari kelompok lain serta tidak membuat yel-yel untuk kelompok. Pada model pembelajaran CRHsiswa tugas untuk menjawab pertanyaanpertanyaan yang sudah disiapkan oleh guru secara berkelompok dan membuat yel-yel untuk kelompoknya. Persamaan model pembelajaran TQdan CRHyaitu pada jumlah anggota dalam kelompoknya dan keduanya menggunakan permainan game dalam proses pembelajarannya. Jumlah anggota dalam kelompok yaitu terdiri dari 4 sampai 6 siswa, sehingga siswa bekerjasama bersama teman-teman kelompoknya (Wakhyuningtiyas, 2016).

\section{METODE PENELITIAN}

Jenis penelitian yang dilakukan yaitu Quasy Experimental Design atau eksperimen semu.Menurut Sugiyono (2013)Quasy Experimental digunakan karena pada kenyataannnya sulit mendapatkan kelompok kontrol yang digunakan untuk penelitian. Desain penelitian yang digunakan dalam penelitian ini yaitu nonequivalent control group design, desain ini hampir sama dengan pretest-posttest control group design, hanya pada desain ini kelas eksperimen eksperimen A maupun kelas eksperimen B yang tidak dipilih secara random.

Dalam penelitian ini, terdapat dua kelas yang disebut kelas eksperimen Adan kelas eksperimen B. Data awal pada penelitian ini berupa hasil belajar siswa yang diambil dari nilai ujian tengah semester ganjil. Perlakuan yang diberikan dalam penelitian ini adalah menerapkan model pembelajaran Team Quiz pada kelas eksperimen A dan model pembelajaran Course Review Horay pada kelas eksperimen B. Pada masing-masing kelas diberikan pretest untuk mengetahui kemampuan awal siswa sebelum diberikan perlakuan, kemudian diakhir penelitian dilakukan posttest untuk mengetahui sejauh mana pengaruh perlakuan yang diberikan.

Penelitian ini dilakukan di SMAN 1 Lingsar, kegiatan penelitian ini berlangsung mulai bulan Juli - September 2018 dengan jumlah populasi seluruh siswa kelas XI MIA sebanyak 131 orang. Sampel dalam penelitian 
ini yaitu siswa kelas XI MIA3 yang berjumlah 34 orang dan siswa Kelas XI MIA 4 yang berjumlah 33orang. Teknik pengambilan sampel (sampling) yang digunakan yaitu teknik purposive sampling.Purposive sampling adalah teknik penentuan sampel dengan pertimbangan tertentu (Sugiyono, 2016).

Variabel bebas dalam penelitian ini adalah pembelajaran menggunakan model Team Quiz untuk kelas eksperimen Adan pembelajaran dengan Course Review Horay untuk kelas eksperimen B. Sedangkan variabel terikat pada penelitian ini adalah hasil belajar siswa.

Penelitian ini menggunakan instrumen tes hasil belajar.Instrumen tes yang digunakan berupa tes objektif dengan bentuk pilihan ganda.Instrumen yang telah disusun terlebih dahulu diuji tingkat validitasnya dengan uji validitas ahli menggunakan statistik Aiken's V dan validitas butir soal menggunakan korelasi biserial.Untuk menguji reabilitas instrumen menggunakan rumus KR-20. Seberapa besar peningkatan nilai siswa dilihat menggunakan uji N-gain. Uji hipotesis dalam penelitian ini menggunakan Gain uji-t. Gain uji-t dilakukan setelah data dianalisis dengan uji normalitas dan homogenitasnya.

\section{HASIL DAN PEMBAHASAN}

Penelitian ini bertujuan untuk mengetahui perbedaanhasil belajar kimia yang signifikan antara model pembelajaran Team Quiz dengan model pembelajaran Course Review Horay pada siswa kelas XI MIA SMAN 1 Lingsar Tahun Ajaran 2018/2019. Pengaruh model pembelajaran ini dapat dilihat dari peningkatan nilai tes awal pretest hingga tes akhir posttest pada ranah kognitif. Pelaksanaan pembelajaran dilakukan pada masing-masing kelas sebanyak 6 kali pertemuan, termasuk kegiatan pretest dan posttest. Kelas eksperimenA diberikan perlakuan yakni menerapkan model pembelajaran Team Quiz dan kelas eksperimen B diberikan perlakuan yakni menerapkan model pembelajaran Course Review Horay.

Peneliti memberikan pretest untuk mengetahui kemampuan awal siswa sebelum diberikan perlakuan model pembelajaran dan posttest untuk mengetahui hasil belajar siswa setelah diberikan perlakuan model pembelajaran.

Setelah melakukan penelitian, diperoleh hasil penelitian yaitukelas eksperimen Adengan menerapkan model pembelajaran Team Quiz tidak terdapat perbedaan yang signifikan pada hasil belajar kimia siswa dengan kelas eksperimen B yang diajarkan menggunakan model pembelajaran Course Review Horay. Gambar nilai rata-rata pretest-posttest kelas eksperimen A dan kelas eksperimen B disajikan pada Gambar 1.

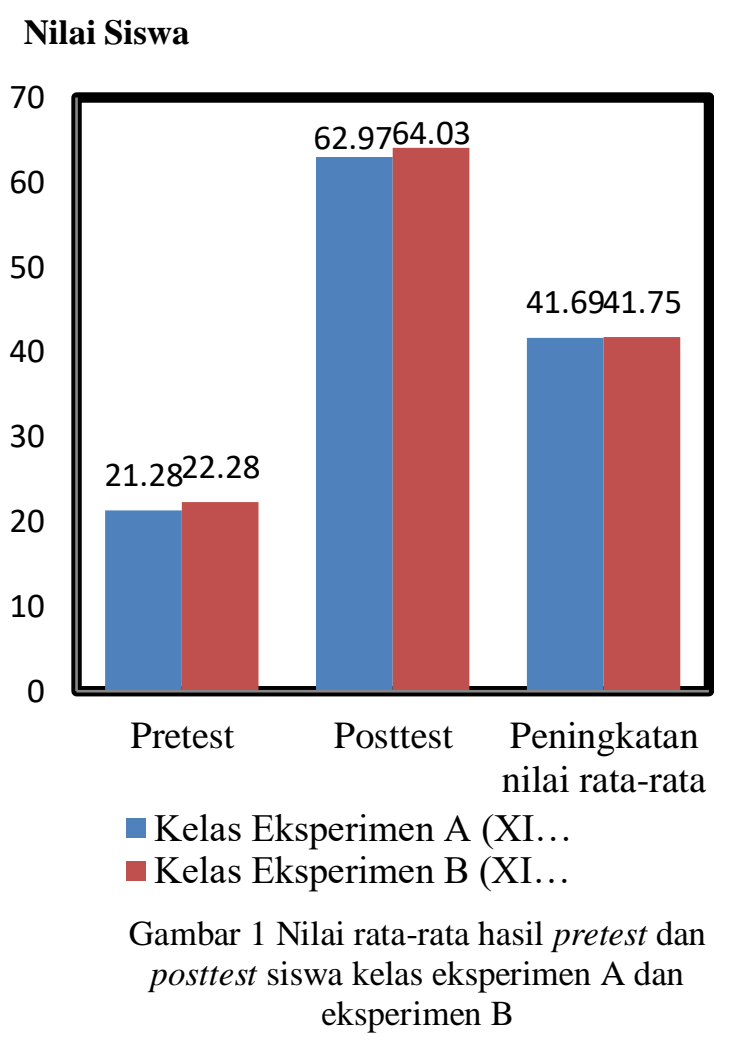

Berdasarkan gambar 1 terlihat bahwa kelas eksperimen A dan kelas eksperimen B dapat meningkatkan hasil belajar. Hal tersebut terlihat dari nilai posstest yang memiliki peningkatan dari nilai pretest.Peningkatan nilai kedua kelas eksperimen dikategorikan peningkatan sedang karena nilai $\mathrm{N}$-gain kelas eksperimen A dan kelas eksperimen B masingmasing adalah 0,52 dan 0,54. Kelas eksperimen B yang menggunakan model pembelajaran Course Review Horay memiliki peningkatan nilai rata-rata yang lebih tinggi dibandingkan kelas eksperimen A yang menggunakan model pembelajaran Team Quiz, yakni 41,69 untuk kelas eksperimen A dan 42,75 untuk kelas eksperimen B.Akan tetapi hal ini tidaklah cukup untuk menyimpulkan bahwa model pembelajaran CRHlebih baik dibandingkan dengan pembelajaran TQ.Hasil perhitungan menggunakan gain uji-t diperolehhasil nilai $t_{\text {hitung }}$ sebesar 0,012 dan nilai tabel sebesar 2,021 yang artinya $t_{\text {hitung }} \leq t_{\text {tabel. }}$. Hal ini menunjukkan bahwa $\mathrm{H}_{0}$ diterima, sehingga dapat disimpulkan bahwa 


\section{Chemistry Education Practice,1 (2), 2018 - 18}

Wardani, Muntari, Hadisaputra, Loka

tidak ada perbedaan hasil belajar kima yang signifikan antara model pembelajaran Team Quiz dengan model pembelajaran Course Review Horay pada siswa kelas XI MIA SMAN 1 Lingsar Tahun Ajaran 2018/2019.

Peningkatan nilai menggunakan model pembelajaran TQ didukung oleh penelitian Krisnawati (2011) yang menunjukkan bahwa penyajian materi dengan menggunakan pembelajaran TQdapat meningkatkan hasil belajar ranah kognitif siswa yang terbukti dari peningkatan ketuntasan siswa setelah diberikan posttest.Begitupula pada penelitian Pratiwi (2016) yang menunjukkan bahwa terjadi peningkatan aktivitas belajar dan prestasi belajar siswa menggunakan model pembelajaran TQ.Peningkatan terjadi disebabkan pemahaman siswa terhadap materi semakin baik dan siswa semakin aktif berdiskusi serta tidak malu untuk bertanya baik kepada teman dalam kelompoknyaa maupun kepada guru hingga benar-benar paham terhadap materi yang diajarkan.

Pada kelas eksperimen B yang menggunakan model pembelajaran Course Review Horay mengalami peningkatan nilai ratarata karena model pembelajaran CRHmembuat semangat belajar yang meningkat karena suasana belajar lebih menyenangkan. Penelitian di lapangan juga menunjukkan bahwa proses pembelajaran dengan menggunakan model pembelajaran ini membuat siswa lebih aktif dan antusias dalam pembelajaran. Oleh karena itu, siswa akan lebih memperhatikan penjelasan guru agar dapat menjawab pertanyaan saat pertandingan game antar kelompok. Siswa juga berdiskusi dengan teman kelompoknya sembari mengerjakan LKS dan apabila siswa masih kurang memahami materi yang diajarkan, siswa dapat bertanya dengan teman kelompoknya dan gurunya.

Peningkatan nilai menggunakan model pembelajaran $\mathrm{CRH}$ didukung oleh penelitian Wahyuningsih (2017) yang menunjukkan bahwa terdapat pengaruh yang signifikan penggunaan model pembelajaran CRH terhadap hasil belajar peserta didik. Peningkatan tersebut diindikasikan pada penerapan model $\mathrm{CRH}$, dimana peserta didik diminta untuk terlibat langsung dalam mempelajari dan memahami secara berkelompok dengan tahapan-tahapan berpikir melalui bahan bacaan, berkomunikasi dalam diskusi kelompok.

\section{KESIMPULAN}

Berdasarkan hasil penelitian dan pembahasan, maka dapat disimpulkan bahwa tidak ada perbedaan hasil belajar kimia yang signifikan antara model pembelajaran Team Quiz dengan model pembelajaran Course Review Horay pada siswa kelas XI MIA SMAN 1 Lingsar Tahun Ajaran 2018/2019.

\section{SARAN}

Diharapkan perlu dilakukanpenelitian lebih lanjut terhadap model pembelajaran Team Quiz dan model pembelajaran Course Review Horaypada materi lain yang dianggap sesuai dengan karateristik model tersebut dan menambahkan hasil belajar dalam ranah afektif dan psikomotorik dan untuk peneliti selanjutnya diharapkan dapat melakukan penelitian dalam jangka waktu yang lebih lama.

\section{DAFTAR PUSTAKA}

Aqib, Z. 2013. Model-model, Media, dan Strategi Pembelajaran Kontekstual (Inovatif).Bandung: Yrama Widya.

Arikunto,S.2016.

DasardasarEvaluasiPendidikanEdisi

2.Jakarta: BumiAksara.

Dalvi. 2006. Guru yang Menggairahkan. Yogyakarta: Gama Media.

Huda, M. 2013. Model Pengaruh dan Pembelajaran. Yogyakarta: Pustaka Pelajar.

Lie, A. 2007. Mempraktikkan Cooperative Learning di Ruang-Ruang Kelas. Jakarta: Grasindo.

Pebriana, L., Sukib, Junaidi, E. 2018. Pengaruh Model Pembelajaran Berbasis Masalah (Problem Based Learning) dengan Tipe Group Investigation (GI) Terhadap Hasil Belajar siswa. Chemistry Education Practice, 1 (1): 6-12.

Sagala, S. 2010. Supervisi Pembelajaran Dalam Profesi Pendidikan. Bandung: Alfabeta.

Silberman, M. L. 2007. Active Learning Strategi Pembelajaran Aktif.Yogyakarta: Pustaka Insan Madani.

Slameto.2013. Belajar dan Faktor-Faktor Yang Mempengaruhi. Jakarta: PT Rineka Cipta.

Sugiyono. 2016. MetodePenelitianKombinasi (Mixed Methods). Bandung: Alfabeta. 


\section{Chemistry Education Practice,1 (2), 2018 - 19}

Wardani, Muntari, Hadisaputra, Loka

Suprijono, A. 2009.Cooperative Learning

(TeoridanAplikasi

PAIKEM).Yogyakarta: PustakaPelajar.

Wakhyuningtiyas, D.2016. Perbedaan Keaktifan

Siswa dalam Pembelajaran Kelas

Menggunakan Metode Team Quiz dan

Course Review Horay di SMPN 4

Wates.Skripsi. Yogyakarta : Universitas

Negeri Yogyakarta. 